\title{
Ionic liquid-based multi-stage sugaring-out extraction of lactic acid from simulated broth and actual lignocellulosic fermentation broth
}

Xu Zhou ${ }^{1}$, Yaqin Sun ${ }^{1 *}$, Hongjun Zhan ${ }^{1}$, Haijun Liu², Xiaoyan Wang ${ }^{2}$, Yang Xu ${ }^{2}$ Yi Li ${ }^{2}$, Zhilong Xiu ${ }^{1}$ and Yi Tong ${ }^{2^{*}}$

\begin{abstract}
In this study, ionic liquid-based sugaring-out extraction was developed to separate lactic acid from the synthetic solution and actual lignocellulosic fermentation broth. Except for $\left[\mathrm{E}_{\mathrm{OH}} \mathrm{mim}\right] \mathrm{BF}_{4}$, the $\mathrm{LLs}_{\mathrm{s}}$ ith $\mathrm{BF}_{4}{ }^{-}$and $\mathrm{OTF}^{-}$anion can form aqueous two-phase system (ATPS) with the aid of saccharides. With the same kind of saccharides, the ATPS formation ability of ILs could be promoted by increasing the side-chain length of ILs in the order of [ $\mathrm{Hmim}] \mathrm{BF}_{4} \approx[\mathrm{Bmim}]$ $\mathrm{BF}_{4}{ }^{\prime}$ [Emim] $\mathrm{BF}_{4}$ due to the decrease in ILs' kosmotropicity. On the other hand, for the same type of ILs, an ATPS was formed more easily with glucose than with xylose. When IL concentration varied from $35 \%(\mathrm{w} / \mathrm{W})$ to $40 \%(\mathrm{~W} / \mathrm{W})$ at a low glucose concentration of $15 \%(\mathrm{w} / \mathrm{W})$, an interesting phase reversal was observed. When lactic acid was undissociated at $\mathrm{pH}$ 2.0, 51.8\% LA and 92.3\% [Bmim] $\mathrm{BF}_{4}$ were partitioned to the top phase, and $97.0 \%$ glucose to the bottom phase using an ATPS consisting of $25 \%(\mathrm{w} / \mathrm{w})$ glucose and $45 \%(\mathrm{w} / \mathrm{W}) \mathrm{IL}$. The total recovery of LA would increase to $89.0 \%$ in three-stage sugaring-out extraction from synthetic solution. In three-stage sugaring-out extraction from the filtered and unfiltered fermentation broth obtained via simultaneous saccharification and co-fermentation (SSCF) of acid-pretreated corn stover by the microbial consortium, the total recovery of LA was $89.5 \%$ and $89.8 \%$, respectively. Furthermore, the total removal ratio of cells and pigments from the unfiltered broth was $68.4 \%$ and $65.4 \%$, respectively. The results support IL-based sugaring-out extraction as a potential method for the recovery of lactic acid from actual fermentation broth.
\end{abstract}

\section{Highlights}

- IL-based sugaring-out extraction was applied to separate LA from fermentation broth

- Different ILs and saccharides consisting systems were examined

- The ability to form ATPS is in the order of $[\mathrm{Hmim}] \mathrm{BF} 4 \approx[\mathrm{Bmim}] \mathrm{BF} 4^{>}[\mathrm{Emim}] \mathrm{BF} 4$

- The partition behaviors of LA, [Bmim]BF4, and saccharides were evaluated

- LA recovery of $89.8 \%$ was obtained with removal of $68.4 \%$ cells and $65.4 \%$ pigments

Keywords: Ionic liquid, Sugaring-out extraction, Lactic acid, Multi-stage, Fermentation broth

\footnotetext{
*Correspondence: sunyaqin@dlut.edu.cn; tongyi@cofco.com

1 school of Bioengineering, Dalian University of Technology, No.2 Linggong Road, Ganjingzi District, Dalian, Liaoning 116024, People's Republic of China

2 Jilin COFCO Biochemistry Co., Ltd. (National Engineering Research Center of Corn Deep Processing), Changchun, Jilin 130033, People's Republic of China
}

(c) The Author(s) 2021. Open Access This article is licensed under a Creative Commons Attribution 4.0 International License, which permits use, sharing, adaptation, distribution and reproduction in any medium or format, as long as you give appropriate credit to the original author(s) and the source, provide a link to the Creative Commons licence, and indicate if changes were made. The images or other third party material in this article are included in the article's Creative Commons licence, unless indicated otherwise in a credit line to the material. If material is not included in the article's Creative Commons licence and your intended use is not permitted by statutory regulation or exceeds the permitted use, you will need to obtain permission directly from the copyright holder. To view a copy of this licence, visit http://creativecommons.org/licenses/by/4.0/. 


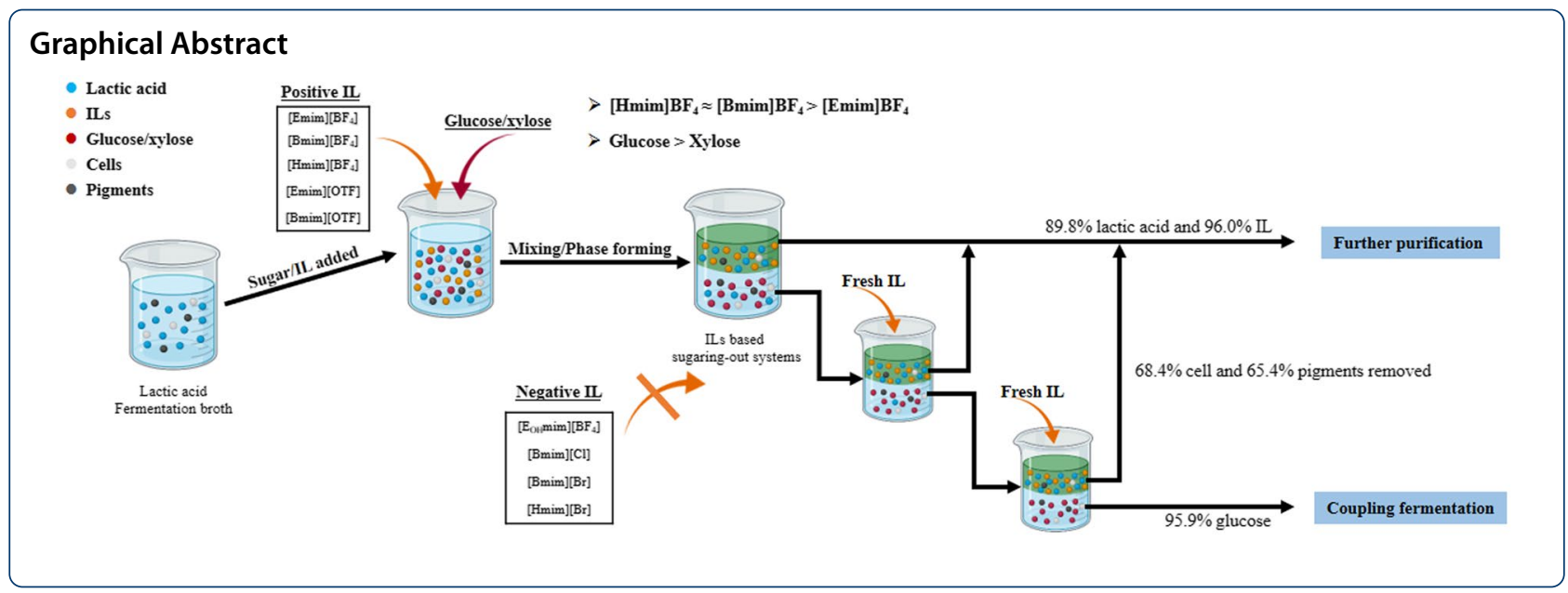

\section{Introduction}

Lactic acid (LA), an important platform chemical, is widely used in the food, pharmaceutical, and chemical industries, particularly as a monomer of biodegradable and biocompatible polylactic acid (Ahmad et al. 2020). Low-cost lignocellulosic feedstocks have received a lot of attention as an alternative carbon source for LA production because they are readily available, sustainable, and renewable (Isikgor and Becer 2015; Yuan et al. 2018). However, lignocellulose-derived lactic acid may produce more impurity components in broth than starch or sugar-based lactic acid production, such as lignin, protein, other organic acid, furan derivatives, and pigments. More complex processes and higher costs are required to separate LA from lignocellulose-derived broth (Xu et al. 2018). Developing an efficient and cost-effective method for separating second-generation LA is both necessary and challenging. As a result, economical and efficient recovery and purification processes for lignocellulosic lactic acid are desired.

Various separation and purification technologies of LA, including precipitation (Meng et al. 2020), extraction (Matsumoto et al. 2003; Oliveira et al. 2012), distillation (Komesu et al. 2017), electrodialysis (Choi et al. 2002), aqueous two-phase (Lan et al. 2019; Xu et al. 2018; Yan et al. 2016), adsorption (Tang et al. 2013; Zhang et al. 2018), and liquid membranes (Matsumoto et al. 2020), have all been thoroughly studied and demonstrated. Among these methods, aqueous two-phase (ATP) is recognized as a promising method for separating biochemicals because of their high selectivity, easy scale-up, and continuous operation mode (Claudio et al. 2014). Up to now, the majority of lactic acid purification ATP systems (ATPSs) were based on polyethylene glycol (PEG)/salt systems (Yankov et al. 2008). Because of the high cost of the polymers and the difficulty in isolating the extracted molecules from the polymer phase by back-extraction, these systems are unlikely to be used to produce bulk chemicals on a large scale (Aydogan et al. 2011). Recently, salting-out extraction systems, comprising short-chain alcohol and inorganic salts, have been successfully used to separate lactic acid due to their high separation efficiency, low cost, low interfacial tension, and ease of scale-up (Aydogan et al. 2011; Fu et al. 2015; Song et al. 2013; Yan et al. 2018, 2016). Salting-out extraction could recover over $87 \%$ lactic acid using the system of $18.40 \%$ $(\mathrm{w} / \mathrm{w})$ dipotassium hydrogen phosphate and 30.23\% (w/w) ethanol (Aydogan et al. 2011). Salting-out extraction ATPS usually happens at high salt concentrations, which may induce unwanted chemical reactions and may not be good for the separation of labile biological components (Lightfoot and Moscariello 2004; Wang et al. 2008a). The recovery and reuse of inorganic salt become the critical factor for the application of saltingout extraction. To avoid using a large amount of salts and to reduce wastewater generation, sugars as the substrates in fermentations for sugar-based chemicals can replace salts to trigger two-phase separation. Sugaringout was firstly proposed by adding a mono-sugar or a disaccharide into an acetonitrile-water mixture (Wang et al. 2008a, b). Compared to sugaring-out system, the sugaring-out extraction ATPS consisting of sugars and solvent has potential advantages in hydrophilic compounds separation (Dai et al. 2015, 2017; Sun et al. 2019; Yan et al. 2016). A sugaring-out extraction system consisting of isopropanol and glucose was investigated to separate lactic acid (Yan et al. 2016). LA recovery of $84.27 \%$ with a partition coefficient of 1.39 was obtained by a system consisting of $12 \%(\mathrm{w} / \mathrm{w})$ glucose and $40 \%$ $(\mathrm{w} / \mathrm{w})$ isopropanol. Lactic acid extraction yields were comparable for short-chain alcohol-based salting-out 
extraction and sugaring-out extraction ATPS. Organic solvents were generally selected as the extractants among the mentioned salting-out extraction and sugaring-out extraction. The high toxicity and volatility of organic solvent limit their use on an industrial scale. In order to minimize environmental impacts about the use of volatile organic compounds, ionic liquid (IL), a green solvent with low volatility at ambient conditions, low toxicity, biocompatibility, and biodegradability, has been used in separation processes (Han and Armstrong 2007). IL could offer an alternative to organic solvents to develop a suitable extraction process because the chemical and physical properties of ILs are tunable by choosing the appropriate anion and cation pair (Muller et al. 2013). Therefore, IL has emerged as a valuable option for forming an ATPS because they typically provide faster phase separation, a significant reduction in viscosity, and the ability to tailor the coexisting phases' polarities in such a way that complete extraction efficiencies can always be predicted (Claudio et al. 2014; Dai et al. 2021). Because of these characteristics, as well as the vast possibility of their ions rearrangement, ILs have an outstanding ability to extract and purify biochemicals. Ionic liquid-based ATPS was demonstrated and applied to separate biochemicals, e.g., succinic acid (Pratiwi et al. 2015; Sun et al. 2018) and 1,3-propanediol (Muller et al. 2013). However, the ionic liquid-based sugaring-out extraction system was never reported to separate lactic acid from actual lignocellulosic fermentation broth.

Hence, the current research sought to investigate the ability of water-miscible ionic liquids and sugars to build aqueous two-phase systems for lactic acid separation. First, the ability of ionic liquids composed of different anions and cations to form an ATPS with the aid of saccharides was investigated. Furthermore, the main factors influencing extraction efficiency were investigated, including IL concentration, saccharides type and concentration, and the dissociation of lactic acid or not. Final, the multi-stage extraction system was applied to extract lactic acid from the corn stover-derived fermentation broth. The partition behaviors of the cell, proteins, and pigments were also studied.

\section{Materials and method Chemicals}

The investigated ILs are listed, together with their abbreviations and chemical structures, in Table 1. All of the ILs were purchased from Chengjie Chemical Co., Ltd. (Shanghai, China) with a purity of greater than 99\%. Glucose, xylose, lactic acid, and other chemicals were purchased from Sinopharm Chemical Reagent Co., Ltd (Shanghai, China) and were analytical grade.

\section{Simulated broth and lignocellulosic fermentation broth}

Simulated broth, including $89.25 \mathrm{~g} / \mathrm{L}$ lactic acid, was prepared. The fermentation broth was obtained from simultaneous saccharification and co-fermentation (SSCF) of dilute acid-pretreated corn stover by microbial consortium (Sun et al. 2021). Corn stover was milled into particles with size $<2 \mathrm{~mm}$ and then was pretreated by $1 \%$ (v/v) dilute $\mathrm{H}_{2} \mathrm{SO}_{4}$ solution with $10 \%$ (w/v) of dry biomass loading. The SSCF process was operated for $110 \mathrm{~h}$, and the final concentrations of LA and residual xylose in the fermentation broth were $34.32 \mathrm{~g} / \mathrm{L}$, and $17.76 \mathrm{~g} / \mathrm{L}$, respectively. The fermentation broth was centrifuged for $20 \mathrm{~min}$ at $4500 \mathrm{rpm}$, which is defined as unfiltered broth. Then the unfiltered broth was filtered by a cellulose triacetate hollow fiber dialyzer (Sureflux-150G) which is defined as filtered broth. As a result, the final concentration of LA and residual xylose in the filtered broth was 29.80 and $15.50 \mathrm{~g} / \mathrm{L}$, respectively.

\section{Binodal curves}

In this study, the binodal curves of ILs with saccharides at $293.15 \mathrm{~K}$ were obtained by the cloud point method according to the published study (Fu et al. 2015). Glucose or xylose solution with varying concentrations was titrated dropwise with ILs until the solution became turbid. The compositions of these mixtures were noted and determined by an analytical balance.

\section{IL-based sugaring-out extraction experiments}

Simulated fermentation broth as described in "Simulated broth and lignocellulosic fermentation broth" Section was used to investigate the influences of sugaring-out extraction system for the partition behaviors of LA, IL, and saccharides in one-stage extraction. The glucose or xylose was dissolved in the simulated and actual fermentation broth to obtain a saccharide mixture. Following that, $[\mathrm{Bmim}] \mathrm{BF}_{4}$ was added into the saccharide mixture and mixed thoroughly by a vortex mixer. The obtained mixture was allowed to stand for $8 \mathrm{~h}$.

The optimized sugaring-out extraction system was then developed in three-stage for simulated broth, unfiltered fermentation broth, and filtered fermentation broth. For the first-stage extraction, $45 \%(\mathrm{w} / \mathrm{w})$ IL and $25 \%(\mathrm{w} / \mathrm{w})$ glucose were added to the broth at $\mathrm{pH}$ 2.0. The glucoserich phase was then prepared for the second and third stages of extraction. Only fresh IL was added in the second and third stages to achieve a sugaring-out extraction system that contained $45 \%(\mathrm{w} / \mathrm{w})$ IL. 
Table 1 Abbreviations and chemical structures of the investigated ILS

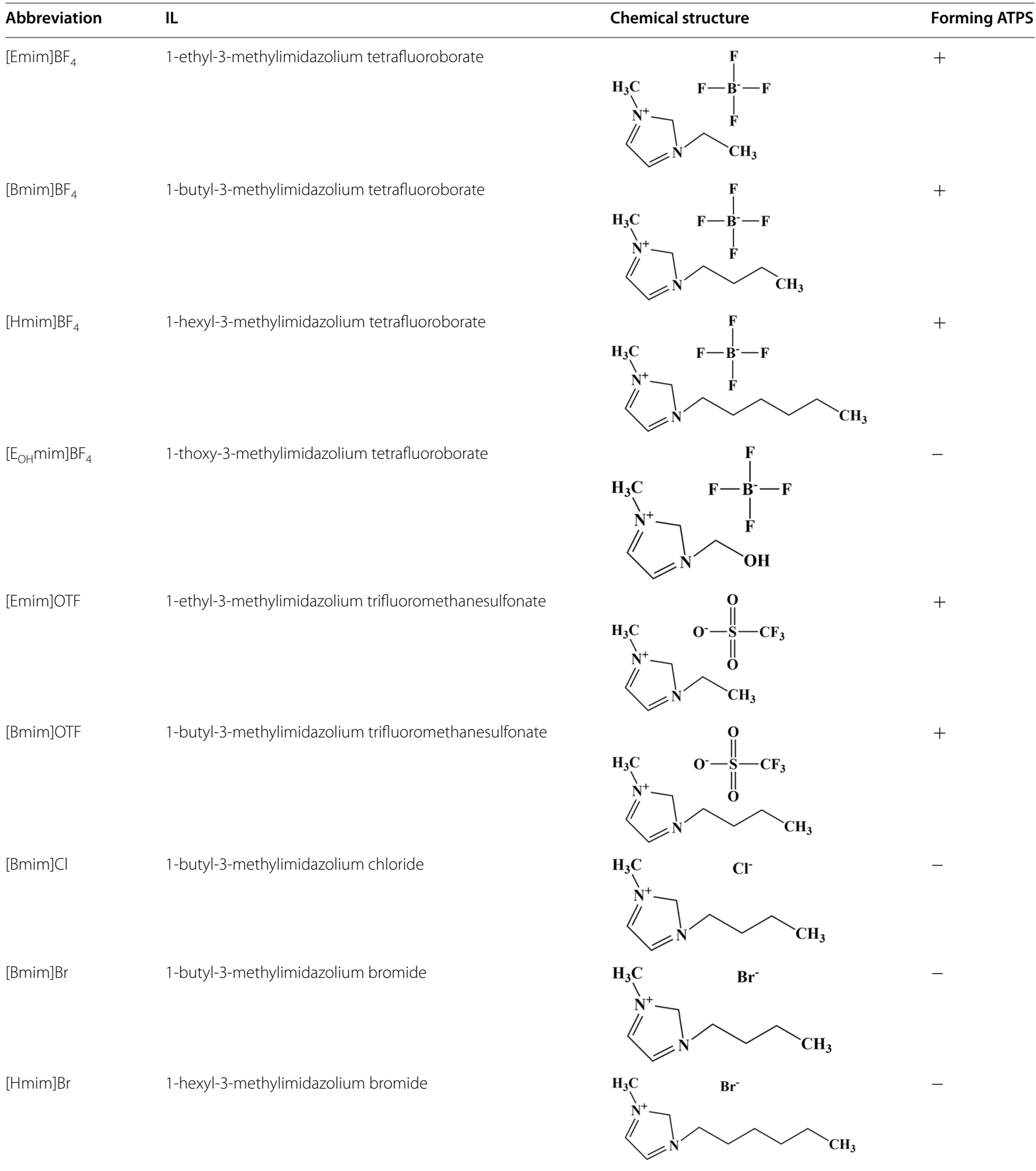

+ represents that it can form an aqueous two-phase, and -represents that it cannot form an aqueous two-phase 
The phase ratio $(R)$, partition coefficient $(K)$, and extractability $(Y)$ for each stage of sugaring-out extraction were defined as our previous report (Sun et al. 2018).

The removal ratio of cells, soluble proteins, and pigments $\left(D_{M i}\right)$ for each stage was defined as follows:

$$
D_{M i}=\left(1-M_{T i} / M_{W i}\right) \times 100 \% \quad i=1,2,3
$$

where $M_{T i}$ is the mass of cells, proteins, and pigments in the top phase and $M_{W i}$ is total mass of cells, proteins, and pigments in the added solution for each stage of sugaring-out extraction system, respectively.

The total extractability of lactic acid and glucose for the three stages of sugaring-out extraction could be calculated as follows:

$$
T Y=\left\{Y_{1}+Y_{2}\left(1-Y_{1}\right)+Y_{3}\left[1-Y_{1}-Y_{2}\left(1-Y_{1}\right)\right]\right\} \times 100 \%,
$$

where $Y_{1}, Y_{2}$, and $Y_{3}$ represent the extraction yield of the 1st, 2nd, and 3rd stages, respectively. The average extractability of three stages was used to calculate the total extractability of IL.

The total removal ratio of cells, soluble proteins, and pigments was defined as follows:

$$
T D_{M}=\prod_{i=1}^{3} D_{M i} .
$$

\section{Analytical methods}

The concentrations of lactic acid, glucose, xylose, and ILs were analyzed using HPLC equipped with an Aminex HPX-87H column with a column temperature of $65{ }^{\circ} \mathrm{C}$. Sulfuric acid $(5 \mathrm{mmol} / \mathrm{L})$ was the mobile phase with a flow rate of $0.6 \mathrm{~mL} / \mathrm{min}$. The biomass concentration was measured by absorbance at $600 \mathrm{~nm}$ using a spectrophotometer. The concentration of soluble proteins was determined by the BCA Protein Colorimetric Assay Kit. The pigments were analyzed and measured by UV spectrophotometry at $320 \mathrm{~nm}$. Each experiment was carried out in triplicate and the mean experimental values are given in the tables and figures.

\section{Results and discussion}

\section{ATPS formation ability of ionic liquids/ saccharides}

To effectively apply IL-based sugaring-out extraction systems as extractive platforms, their phase diagrams must be established experimentally. Table 1 shows the results of ILs forming aqueous two-phase systems with saccharides. The ILs with $\mathrm{BF}_{4}{ }^{-}$anion, with the exception of $\left[\mathrm{E}_{\mathrm{OH}} \mathrm{mim}\right] \mathrm{BF}_{4}$ and $\mathrm{OTF}^{-}$anion, can form ATP systems with glucose or xylose. However, the investigated ILs with $\mathrm{Br}^{-}$and $\mathrm{Cl}^{-}$anion cannot form an ATPS with saccharides. Previous research found that 1-alkyl-3-methyl imidazolium chloride $\left(\left[\mathrm{C}_{n} \mathrm{mim}\right] \mathrm{Cl}, n=2\right.$ to 10$)$ and 1-alkyl-3-methyl imidazolium bromide $\left(\left[\mathrm{C}_{n} \mathrm{mim}\right] \mathrm{Br}\right.$, $n=2$ to 10) never form ATPS with carbohydrate in temperatures ranging from $242.15 \mathrm{~K}$ to $373.15 \mathrm{~K}$, whereas $\left[\mathrm{C}_{n} \mathrm{mim}\right] \mathrm{Cl} \quad(\mathrm{n}=1)$ and $\left[\mathrm{C}_{n} \mathrm{mim}\right] \mathrm{Br} \quad(\mathrm{n}=1)$ can form ATPS with sucrose (Chen et al. 2009; Wu et al. 2008a). $\mathrm{BF}_{4}{ }^{-}$is generally recognized as a chaotropic anion, and the imidazolium ring is recognized as a kosmotropic cation. However, the effect of imidazolium-based cation hydration is inconclusive when compared to the hydration of $\mathrm{BF}_{4}^{-}$(Wu et al. 2008b). As a result, it appears reasonable to consider imidazolium tetrafluoroborate as a chaotropic IL. Among the four imidazolium tetrafluoroborate ILs studied, $\left[\mathrm{E}_{\mathrm{OH}} \mathrm{mim}\right]^{+}$is more kosmotropic than $[\mathrm{Emim}]^{+}$. Therefore, it is difficult to form an ATPS for $\left[\mathrm{E}_{\mathrm{OH}} \mathrm{mim}\right]^{+}$with saccharides. Moreover, the anion $\mathrm{Cl}^{-}$and $\mathrm{Br}^{-}$are more hydrophilic than $\mathrm{BF}^{-}$, it is also difficult to form ATPS for $\mathrm{Cl}^{-}$and $\mathrm{Br}^{-}$anion when mixed with kosmotropic solutions.

Figure 1 depicts the binodal curves of the $\mathrm{BF}_{4}{ }^{-}$anion ATPS with glucose or xylose. When the same types of saccharides investigated, it was discovered that increasing the side-chain length of ILs could promote the formation of an ATPS. The kosmotropicity of ILs decreased as their side-chain length increased. Therefore, the phase separation abilities of ILs with the same kind of saccharides are in the order of $[\mathrm{Hmim}] \mathrm{BF}_{4} \approx[\mathrm{Bmim}] \mathrm{BF}_{4}>[\mathrm{Emim}] \mathrm{BF}_{4}$ as shown in Fig. 1. Furthermore, -OH groups on sugar molecules that destroy the natural hydrogen-bonded water network, as well as the stereochemistry of saccharides, have a significant impact on the formation of ATPS. The more hydroxyl groups there are in a saccharide, the more kosmotropic the saccharide. The mean number of the equatorial hydroxyl group of glucose and xylose are 4.56

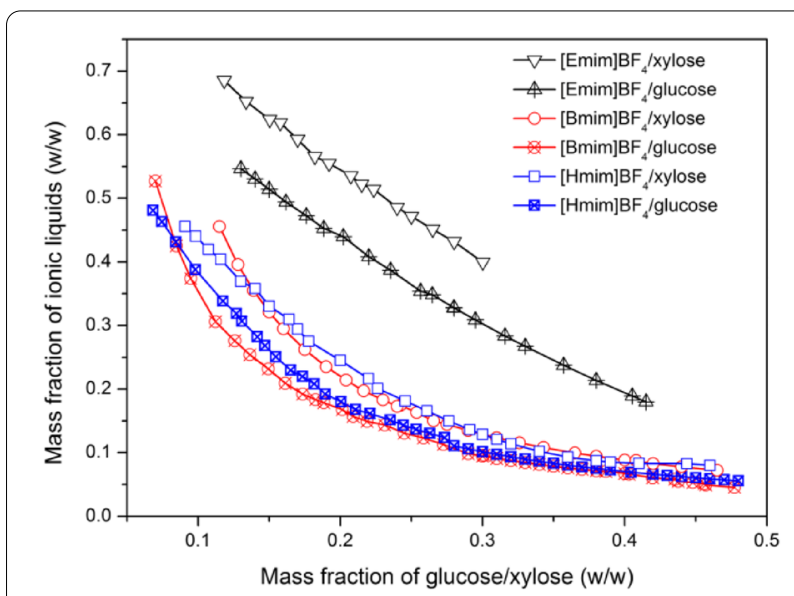

Fig. 1 Binodal curves for $\mathrm{BF}_{4}{ }^{-}$anion ILs + glucose $+\mathrm{H}_{2} \mathrm{O}$ system, $\mathrm{BF}_{4}{ }^{-}$anion ILs + xylose $+\mathrm{H}_{2} \mathrm{O}$ system at $298.15 \mathrm{~K}$ 
and 3.67, respectively (Wu et al. 2008b). Therefore, glucose is more kosmotropic than xylose, and the ability to form an ATPS of glucose is stronger than that of xylose. Previous reports systematically studied the liquid-liquid equilibria of the $[\mathrm{Bmim}] \mathrm{BF}_{4}$ with fructose and sucrose system (Wu et al. 2008a, b; Zhang et al. 2007). It was discovered that $[\mathrm{Bmim}] \mathrm{BF}_{4} /$ fructose and $[\mathrm{Bmim}] \mathrm{BF}_{4 /}$ sucrose ATPS can be formed over a wide component range, with the ability to form ATPS in the order of sucrose $>$ glucose $>$ xylose $>$ fructose.

For the production of LA from lignocellulosic biomass, a mixture of glucose and xylose is obtained, as we all know. Due to the strong ability of $[\mathrm{Bmim}] \mathrm{BF}_{4}$ to form ATPS with glucose and xylose, the partition behaviors of $\mathrm{LA}$, saccharides, and $[\mathrm{Bmim}] \mathrm{BF}_{4}$ were investigated and analyzed in the following study.

\section{Partition behavior of LA, saccharides, and IL in ATPS of $\left[\mathrm{Bmim}_{\mathrm{B}} \mathrm{BF}_{4} /\right.$ saccharide}

In this study, the aqueous two-phase systems of [Bmim] $\mathrm{BF}_{4} /$ glucose and $[\mathrm{Bmim}] \mathrm{BF}_{4} /$ xylose were investigated to extract lactic acid from the simulated broth. The effect of $[\mathrm{Bmim}] \mathrm{BF}_{4}$ and saccharides concentration on the distribution behaviors of $\mathrm{LA},[\mathrm{Bmim}] \mathrm{BF}_{4}$, and saccharides was investigated and is shown in Figs. 2 and 3. The IL was apt to the top phase, while glucose and xylose were apt to the bottom phase, especially in the high mass fraction of saccharide and IL in ATPS. An apparent phase reversal was observed when the IL concentration was varied from $35 \%(\mathrm{w} / \mathrm{w})$ to $40 \%(\mathrm{w} / \mathrm{w})$ at a low glucose concentration of $15 \%(\mathrm{w} / \mathrm{w})$. The concentration of ionic liquid required for phase reversal gradually decreased as the concentration of glucose increased. When the ATPS contained 25\% $(\mathrm{w} / \mathrm{w})$ glucose and $15 \%(\mathrm{w} / \mathrm{w})[\mathrm{Bmim}] \mathrm{BF}_{4}$, over $98 \%$ glucose and 52\% IL were extracted to the top phase. When the IL mass fraction was increased to $20 \%(\mathrm{w} / \mathrm{w})$, only $5 \%$ glucose was distributed to the top phase. In the xylosebased sugaring-out extraction system, phase reversal was also observed (Fig. 3D). A high phase ratio was achieved while abundant glucose and IL were extracted to the top phase, resulting in high lactic acid extractability. The residual glucose or xylose was concentrated on the top phase, which hampered further purification of LA.

At a mass fraction of saccharide greater than 25\% $(\mathrm{w} / \mathrm{w})$ and IL greater than $20 \%(\mathrm{w} / \mathrm{w})$, the partition coefficient of $\mathrm{LA}$ and $[\mathrm{Bmim}] \mathrm{BF}_{4}$ increased with increasing IL concentration. The increase in the partition coefficient for $[\mathrm{Bmim}] \mathrm{BF}_{4}$ was obviously accompanied by a small increase in the partition coefficient for LA. At the same conditions, the partition coefficient of saccharide exhibited the opposite trend. When the IL concentration was increased from $20 \%(\mathrm{w} / \mathrm{w})$ to $45 \%(\mathrm{w} / \mathrm{w})$ at a $25 \%$ $(\mathrm{w} / \mathrm{w})$ glucose concentration, the phase ratio increased from 0.21 to 1.22 . As a result, at a sugaring-out extraction system consisting of $25 \%(\mathrm{w} / \mathrm{w})$ glucose and $45 \%$ $(\mathrm{w} / \mathrm{w}) \mathrm{IL}$, approximately $51.8 \% \mathrm{LA}$ and $92.3 \%\left[\mathrm{Bmim}^{\mathrm{B}} \mathrm{BF}_{4}\right.$ were extracted to the top phase and $97.0 \%$ glucose was extracted to the bottom phase. The extraction efficiency of the xylose-based ATPS is lower than that of the glucose-based ATPS. About 45.9\% LA and 88.7\% [Bmim] $\mathrm{BF}_{4}$ were extracted to the top phase, and $91.6 \%$ xylose was extracted to the bottom phase at a sugaring-out extraction system consisting of $25 \%(\mathrm{w} / \mathrm{w})$ xylose and $45 \%$ (w/w) IL.

The phase ratio decreased as the concentration of saccharides increased, and the partition coefficient of $[\mathrm{Bmim}] \mathrm{BF}_{4}$ increased rapidly. As a result, the extractability of IL increased from $25.0 \%$ to $91.0 \%$ when the glucose concentration was increased from $15 \%(\mathrm{w} / \mathrm{w})$ to $35 \%(\mathrm{w} / \mathrm{w})$ with $\left[\mathrm{Bmim} \mathrm{BF}_{4}\right.$ at $35 \%(\mathrm{w} / \mathrm{w})$. The partition coefficient of LA showed a nearly constant trend, and the extractability decreased from $60.1 \%$ to $48.8 \%$ due to a decrease in phase ratio from 1.41 to 0.81 . Glucose was apt to the top phase at a low mass fraction of glucose in the sugaring-out extraction system. As a result, a high partition coefficient of glucose was obtained in the low mass fraction of glucose and IL selected. The partition coefficient for glucose reached up to 5.32 at $15 \%(\mathrm{w} / \mathrm{w})$ glucose and $35 \%(\mathrm{w} / \mathrm{w})[\mathrm{Bmim}] \mathrm{BF}_{4}$ selected. An increase in the glucose concentration caused as decrease in the partition coefficient of glucose to 0.04 at $25 \%(\mathrm{w} / \mathrm{w})$ glucose and $35 \%(\mathrm{w} / \mathrm{w})\left[\mathrm{Bmim}^{2} \mathrm{BF}_{4}\right.$ selected. Accordingly, $87.7 \%$ and $2.0 \%$ glucose was extracted to the top phase in $15 \%(\mathrm{w} / \mathrm{w})$ glucose and $25 \%(\mathrm{w} / \mathrm{w})$ glucose ATPS, respectively.

In a previous study, a sugaring-out system consisting of $45 \%(\mathrm{w} / \mathrm{w})[\mathrm{Bmim}] \mathrm{BF}_{4}$ and $30 \%(\mathrm{w} / \mathrm{w})$ glucose at $\mathrm{pH}$ 2.0 yielded a relatively high partition coefficient of 2.53 and an extractability of $75.96 \%$ for succinic acid (Sun et al. 2018). Lactic acid had a lower extractability than succinic acid. Lactic acid's kosmotropic ability was more potent than succinic acid's due to the greater number of hydroxyl groups in lactic acid. As a result, lactic acid was more easily distributed to the kosmotropic phase than succinic acid because $[\mathrm{Bmim}] \mathrm{BF}_{4}$ was chaotropic and saccharide was kosmotropic.

Based on the partitioning behaviors of LA, saccharide, and $\left[\mathrm{Bmim}^{-} \mathrm{BF}_{4}\right.$ in sugaring-out extraction systems, a $25 \%(\mathrm{w} / \mathrm{w})$ glucose and $45 \%(\mathrm{w} / \mathrm{w})\left[\mathrm{Bmim}^{\mathrm{B}}\right] \mathrm{BF}_{4}$ system was chosen for further investigation. Figure 4 depicts the relationship between the equilibrium $\mathrm{pH}$ and the extractability of LA. Our previous study found that a $\mathrm{pH}$ lower than the $\mathrm{pK}$ of organic acid causes high extractability and is beneficial for organic acid recovery in sugaringout and salting-out extraction systems. The effect of $\mathrm{pH}$ on LA partition behavior in ionic liquid-based sugaring-out extraction systems was similar. Lactic acid has a 

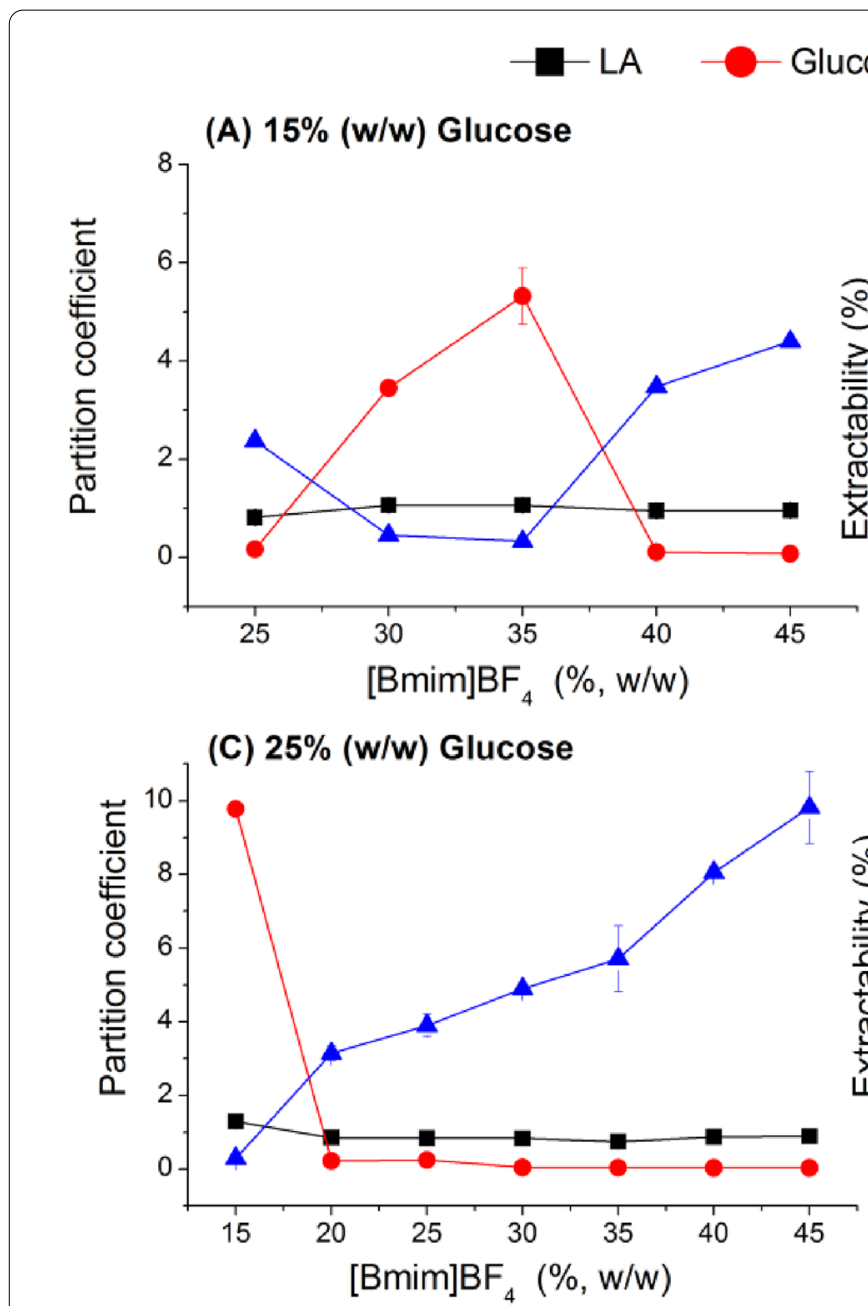

(E) $35 \%(w / w)$ Glucose

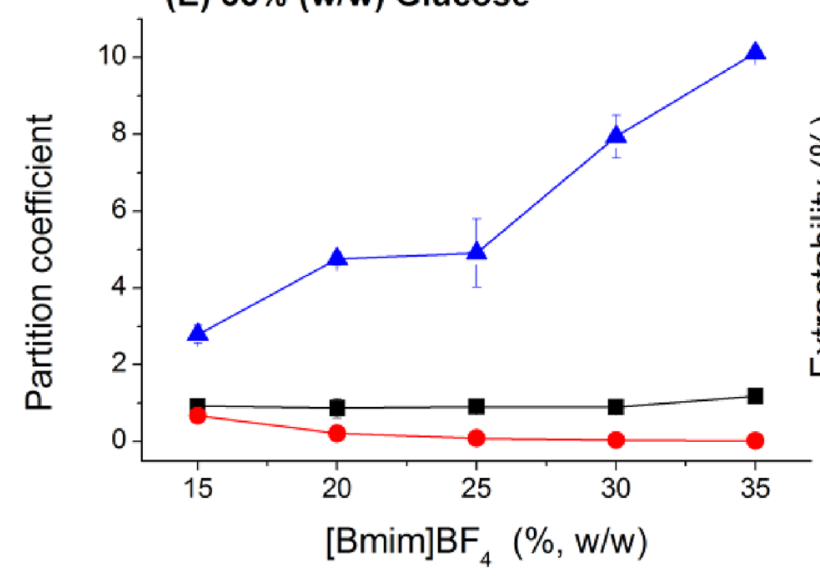

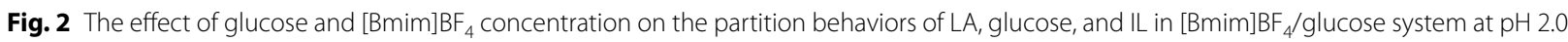

dissociation constant of about 3.86. As a result, 55.1\% LA was recovered to the IL-rich phase at $\mathrm{pH} 1.94$, whereas only $14.1 \%$ LA was extracted to the IL-rich phase at $\mathrm{pH}$
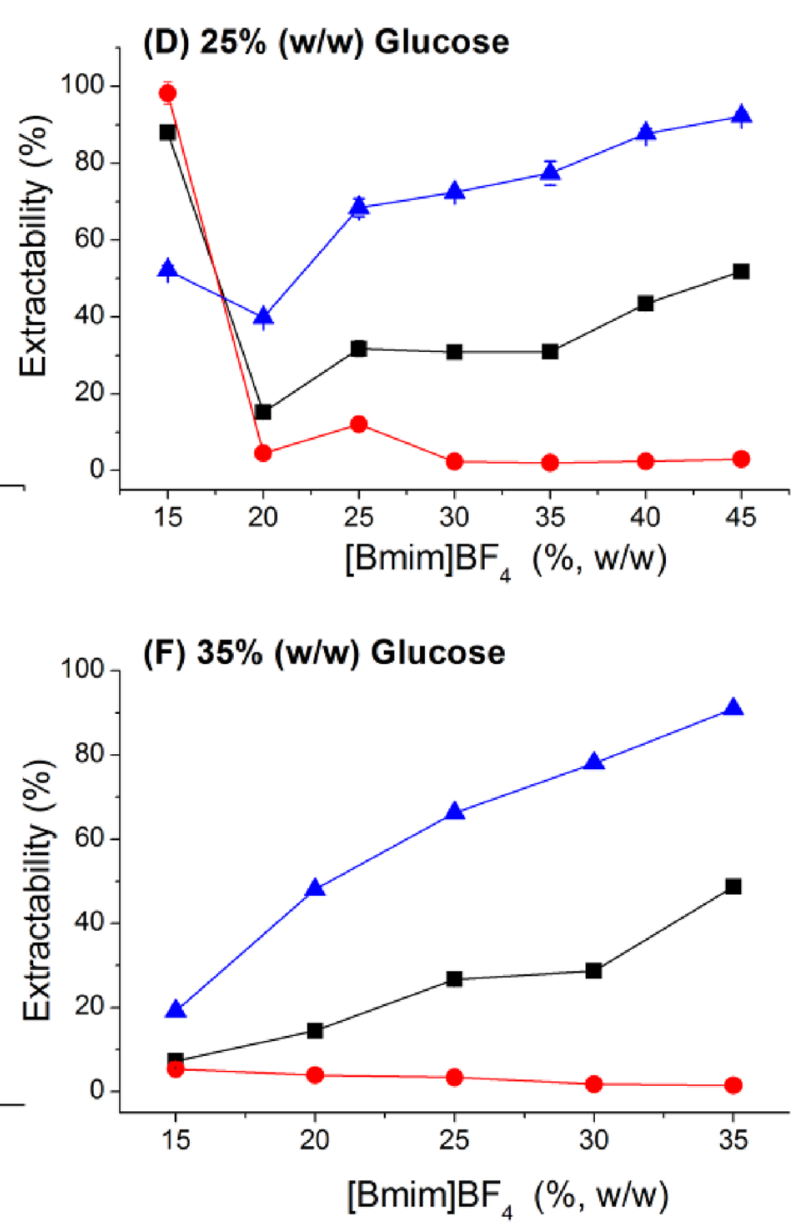

(B) $15 \%(w / w)$ Glucose

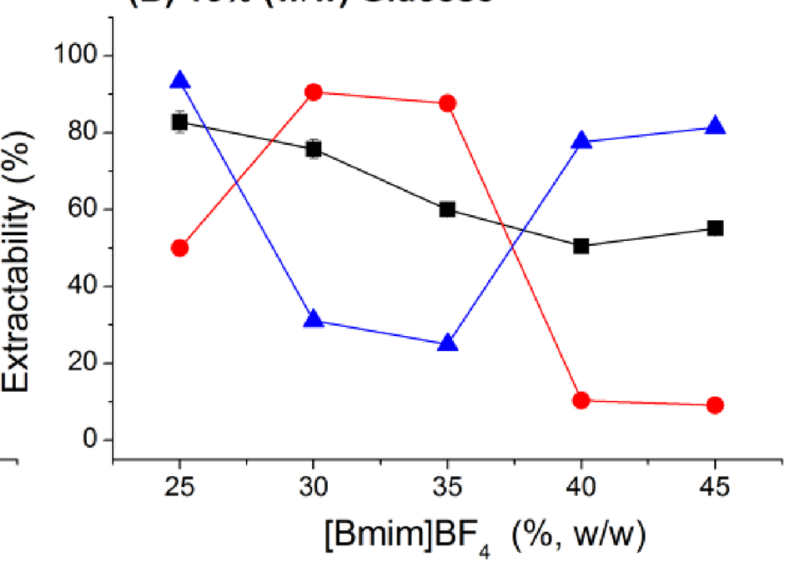

(D) $25 \%(w / w)$ Glucose

(F) $35 \%(w / w)$ Glucose

3.96. Even when the $\mathrm{pH}$ was raised to 6.94 , only $4.0 \%$ of the LA was distributed to the top phase. The $\mathrm{pH}$ change had almost no effect on the partition behavior of glucose 

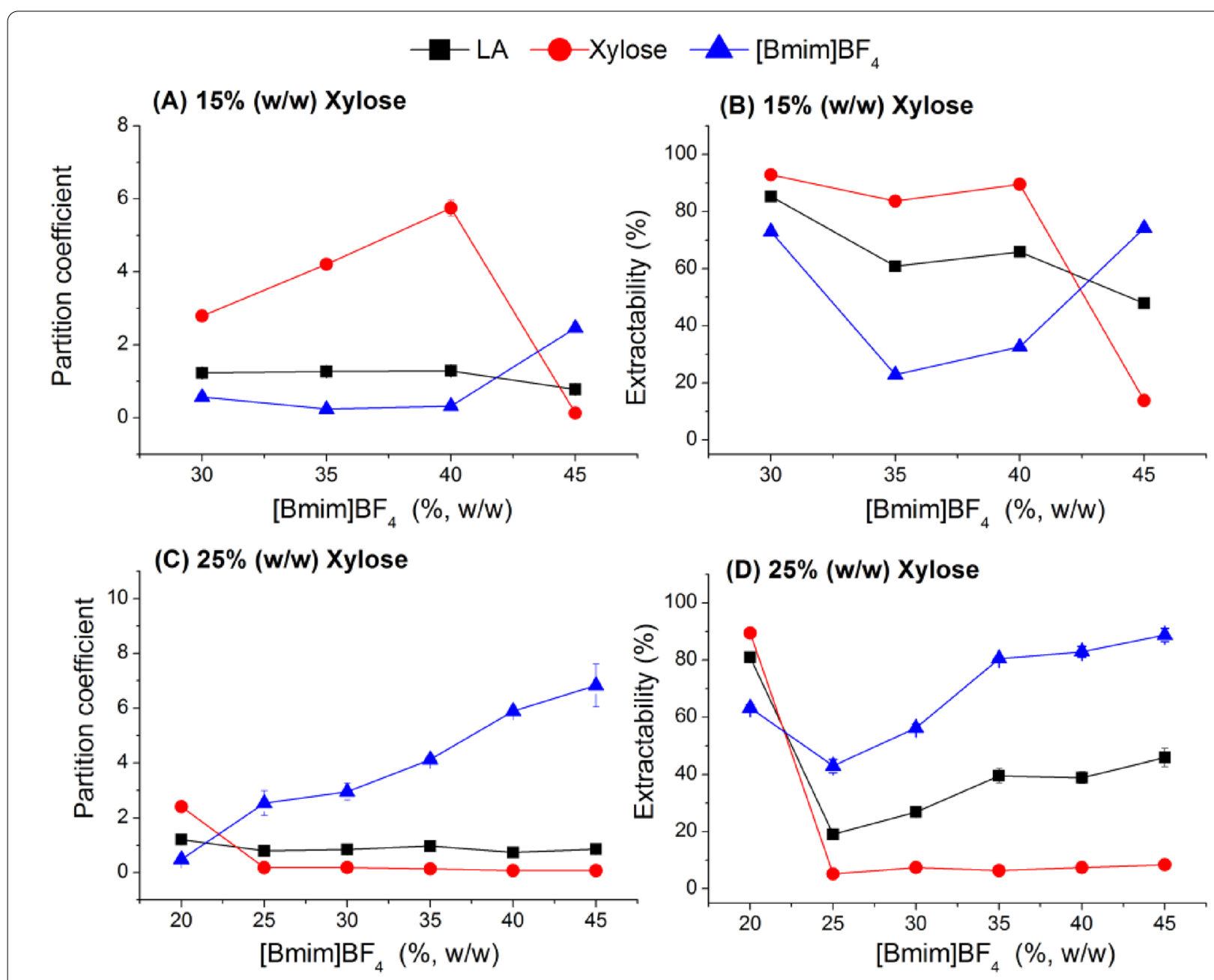

(E) $35 \%(w / w)$ Xylose
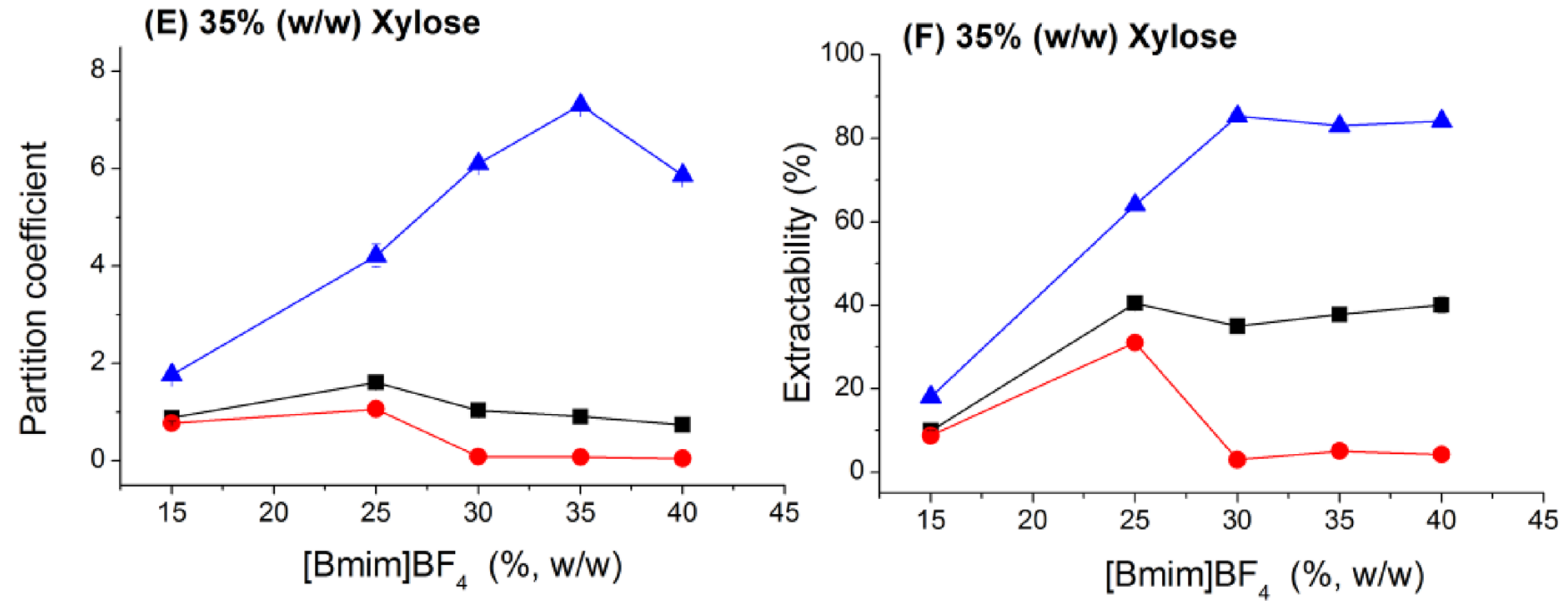

Fig. 3 The effect of xylose and $\left[\mathrm{Bmim}_{\mathrm{B}} \mathrm{BF}_{4}\right.$ concentration on the partition behaviors of $\mathrm{LA}$, xylose, and IL in $\left[\mathrm{Bmim}^{\mathrm{B}} \mathrm{BF}_{4} / \mathrm{xylose}\right.$ system at pH 2.0

and $[\mathrm{Bmim}] \mathrm{BF}_{4}$. About $98 \%[\mathrm{Bmim}] \mathrm{BF}_{4}$ was distributed to the top phase, and $90 \%$ glucose was distributed to the bottom phase when the $\mathrm{pH}$ was varied from 1.94 to 6.94.
The mechanism of ATPS formation and the partition behavior of lactic acid at different $\mathrm{pHs}$ can be explained by the hydration theory. As a process of ionic hydration, 


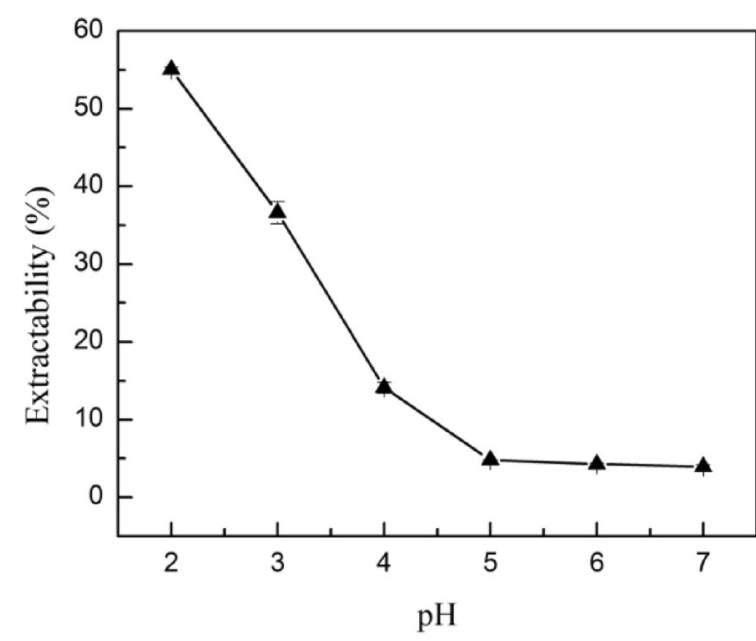

Fig. 4 Relationship between equilibrium $\mathrm{pH}$ and extractability of lactic acid in $45 \%(\mathrm{w} / \mathrm{W})\left[\mathrm{Bmim}^{\mathrm{B}} \mathrm{BF}_{4}\right.$ and $25 \%(\mathrm{w} / \mathrm{w})$ glucose system

when a saccharide is dissolved in an aqueous solution, its ions are surrounded by a layer of water molecules. The formation of IL and saccharide ATPS may be considered to be a competition between the hydrophilic IL and the saccharide for the water molecules. The competition was won by the ions which have a stronger affinity for the water. As illustrated in "ATPS formation ability of ionic liquids/ saccharides" Section, ILs tend to be chaotropic (water-destructuring) salts and saccharides tend to be kosmotropicity (water-structuring). Therefore, water molecules migrated away from the ions of the IL to those of the saccharide. As a result, the hydration and the solubility of the ILs decreased. Consequently, an IL-rich phase separates from the rest of the solution of saccharide. The hydrophobicity parameters $(\log \mathrm{P})$ of lactic acid and sodium lactate were -0.548 and -1.883 , respectively. The large the $\log \mathrm{P}$, the more hydrophobic it is. Therefore, lactic acid was more hydrophobic than sodium lactate. As a result, lactic acid was apt to the chaotropic IL-rich phase and lactate was apt to the kosmotropic saccharide-rich phase. It is also stated that in the alcohol/IL-rich phase, undissociated organic acid may be integrated into the hydrogen-bonding network (Sun et al. 2018; Wakisaka and Ohki 2005).

\section{Multi-stage sugaring-out extraction of LA from synthetic solution and fermentation broth}

In this study, multi-stage separation of lactic acid from simulated broth and actual fermentation broth obtained via SSCF process from corn stover by microbial consortium was investigated and applied. The outcomes were compared and are shown in Table 2. Through three stages of sugaring-out extraction of filtered and unfiltered fermentation broth, the total LA extractability of $89.5 \%$ and $89.8 \%$ was obtained, respectively, which is comparable to the total LA extractability of $89.0 \%$ from the simulated fermentation broth. It was worth noting that the residual xylose in the fermentation broth, which accounted for about 0.53 percent $(\mathrm{w} / \mathrm{w})$, aided the extraction efficiency of LA. Furthermore, the salts in the fermentation medium improved the extractability of lactic acid.

As a result, the total extraction yield of LA for the actual fermentation broth was comparable to that of the simulated broth, which only contained lactic acid. In a previous report, inorganic salts were considered to assist the extraction to enhance extractability of succinic

Table 2 Multi-stage extraction lactic acid by [Bmim]BF4/glucose systems from synthetic solution and lignocellulosic biomass-derived broth at $\mathrm{pH} 2.0$

\begin{tabular}{|c|c|c|c|c|c|c|c|c|c|c|}
\hline \multirow[t]{2}{*}{ Solution Stage } & & \multirow[t]{2}{*}{$\mathbf{R}$} & \multicolumn{3}{|l|}{$\mathrm{K}$} & \multicolumn{3}{|c|}{$Y(\%)$} & \multicolumn{2}{|c|}{$\mathrm{D}_{\mathrm{M}}(\%)$} \\
\hline & & & LA & Glucose & IL & LA & Glucose & IL & Cell & Pigments \\
\hline \multirow[t]{4}{*}{ Synthetic solution } & $1 \mathrm{st}$ & 1.16 & 0.99 & 0.02 & 10.02 & 53.4 & 2.7 & 92.1 & - & - \\
\hline & 2nd & 1.11 & 0.99 & 0.02 & 11.40 & 52.2 & 2.5 & 92.7 & - & - \\
\hline & $3 r d$ & 1.04 & 1.00 & 0.02 & 12.27 & 50.8 & 1.8 & 92.7 & - & - \\
\hline & Total & - & - & - & - & 89.0 & 6.8 & 92.5 & - & - \\
\hline \multirow[t]{4}{*}{ Filtered broth } & 1st & 1.12 & 0.87 & 0.02 & 12.40 & 49.2 & 1.8 & 93.3 & 84.9 & 72.8 \\
\hline & 2nd & 1.05 & 1.06 & 0.02 & 23.86 & 52.8 & 2.0 & 95.1 & 90.9 & 86.5 \\
\hline & $3 r d$ & 1.08 & 1.18 & 0.03 & 41.15 & 56.2 & 3.1 & 97.4 & 91.5 & 90.5 \\
\hline & Total & - & - & - & - & 89.5 & 6.6 & 95.2 & 70.6 & 57.0 \\
\hline \multirow[t]{4}{*}{ Unfiltered broth } & $1 s t$ & 1.03 & 0.94 & 0.02 & 12.62 & 49.2 & 1.7 & 92.8 & 83.9 & 78.5 \\
\hline & 2nd & 1.02 & 1.10 & 0.01 & 33.99 & 52.1 & 1.1 & 97.1 & 88.8 & 90.0 \\
\hline & $3 r d$ & 0.95 & 1.51 & 0.02 & 54.04 & 58.2 & 1.4 & 98.0 & 91.9 & 92.7 \\
\hline & Total & - & - & - & - & 89.8 & 4.1 & 96.0 & 68.4 & 65.4 \\
\hline
\end{tabular}


acid in a solvent-based sugaring-out extraction system. When the mass fraction of $\left(\mathrm{NH}_{4}\right)_{2} \mathrm{SO}_{4}$ was increased from 1 to $9 \%(\mathrm{w} / \mathrm{w})$, the recovery of succinic acid from the broth increased from $87.6 \%$ to $89.6 \%$. The addition of $\left(\mathrm{NH}_{4}\right)_{2} \mathrm{SO}_{4}$ improves the recovery of succinic acid and enhances the $t$-butanol distributed to the top phase and glucose distributed to the bottom phase. In this study, salts in the lignocellulose-derived fermentation broth had a non-negligible effect on the partition behavior of $[\mathrm{Bmim}] \mathrm{BF}_{4}$. The ionic liquid with $\mathrm{BF}_{4}{ }^{-}$anion showed the ability to form two-phase not only with glucose but also with salts (Sun et al. 2018; Li et al. 2009). The mechanism of ATPS formation is both under the label of hydration theory (Trindade et al. 2007). The kosmotropic ions of salts, $\mathrm{PO}_{4}{ }^{3-}, \mathrm{CO}_{3}{ }^{2-}, \mathrm{SO}_{4}{ }^{2-}, \mathrm{H}_{2} \mathrm{PO}_{4}{ }^{-}, \mathrm{OH}^{-}$, and $\mathrm{Cl}^{-}$, which exhibit stronger interaction with water molecules, are beneficial to the ATPS formation. As the [Bmim] $\mathrm{BF}_{4}$ is a chaotropic (water-destructuring) IL, it was apt to the top phase with the aid of salts in the fermentation medium. As a result, more than $95 \%[\mathrm{Bmim}] \mathrm{BF}_{4}$ was extracted to the top phase in unfiltered and filtered fermentation broth during the second and third stages, which was higher than in simulated broth. The use of $[\mathrm{Bmim}] \mathrm{BF}_{4}$ as phase-forming components in sugaringout extraction systems has led to outstanding extraction performances for LA. Nevertheless, IL regeneration, recycling, or reuse lagged behind and still remain a challenging task toward the development of greener costeffective processes. In previous studies, electrodialysis, back-extraction using $\mathrm{Na}_{2} \mathrm{CO}_{3}$, nanofiltration membrane, ion-exchange resin, and rotary evaporation stripped with compressed air were developed to separate and recover the targets and ILs (Claudio et al. 2014; Muller et al. 2013; Sui et al. 2018; Wang et al. 2012, 2016). Over 94\% IL was recovered via back-extraction (Claudio et al. 2014). More than $95 \%$ of $[\mathrm{Bmim}] \mathrm{BF}_{4}$ could be absorbed by the resins of Amberlite IR $120 \mathrm{Na}$ at $20{ }^{\circ} \mathrm{C}$ with contact time of $30 \mathrm{~min}$ (Sui et al. 2018). Moreover, the recovered IL was as effective as fresh IL for 1,3-propanediol extraction (Muller et al. 2013). In this study, these strategies for LA and IL recovery might be reasonable and optional.

Furthermore, approximately $95 \%$ glucose was present in the bottom phase at the same operation condition, which can be reutilized as a fermentation medium to achieve fermentation and separation coupling. In our previous work, the glucose-rich bottom phase in organic solvent-based sugaring-out extraction systems has been successfully reutilized for lactic acid, 2,3-butandiol, and acetoin fermentation (Dai et al. 2015, 2017; Yan et al. 2016). The bacterial growth, glucose consumption, and lactic acid production showed different trends in the three kinds medium of glucose-rich phase, glucose-rich phase with yeast extract addition, and the fresh medium (Yan et al. 2016). The bacteriostatic effect is obvious in the glucose-rich phase-based medium. However, lactic acid yield in the medium of glucose-rich phase with yeast extract addition is similar as it in the fresh medium. As a result, a final lactic acid titer of $130 \mathrm{~g} / \mathrm{L}$ with a yield of $0.91 \mathrm{~g} / \mathrm{g}$ was obtained. Due to the toxicity of $[\mathrm{Bmim}] \mathrm{BF}_{4}$ to microorganisms, the concentration of $[\mathrm{Bmim}] \mathrm{BF}_{4}$ that remained in the bottom phase was critical for utilizing the glucoserich phase. In general, the toxicity of ILs appears to be directly proportional to the length of the alkyl chain and the number of alkyl groups substituted on the cation. ILs with alkyl groups containing 10 and 14 carbon atoms are toxic to bacteria and fungi (Yu et al. 2016). In addition, enzymes are typically inactive in ILs containing the anions $\mathrm{NO}_{3}^{-}, \mathrm{CH}_{3} \mathrm{CO}_{2}{ }^{-}, \mathrm{CF}_{3} \mathrm{CO}_{2}{ }^{-}$, and $\mathrm{CF}_{3} \mathrm{SO}_{3}{ }^{-}$, but active in ILs containing the anions $\mathrm{BF}_{4}{ }^{-}$, $\mathrm{PF}_{6}{ }^{-}$, and $\mathrm{Tf}_{2} \mathrm{~N}^{-}$(Kaar et al. 2003). Thus, designing ILs with alkyl groups shorter than 10 carbon atoms and $\mathrm{BF}_{4}{ }^{-}$anions may help avoid microbial toxicity (Pernak et al. 2003). [Bmim] $\mathrm{BF}_{4}$ was toxic to the growth of Escherichia coli, Pichia pastoris, and Bacillus at 1\% (v/v), which equals approximately $12.15 \mathrm{~g} / \mathrm{L}$ (Ganske and Bornscheuer 2006). In this study, only $2 \%(\mathrm{w} / \mathrm{w})$ $[\mathrm{Bmim}] \mathrm{BF}_{4}$ remained in the bottom phase after threestage sugaring-out extraction. The final concentration of $[\mathrm{Bmim}] \mathrm{BF}_{4}$ and glucose in the bottom phase was $17.70 \mathrm{~g} / \mathrm{L}$ and $577.96 \mathrm{~g} / \mathrm{L}$, respectively. To ferment, the high glucose concentration in the bottom phase must be diluted 5-6 times, with a concentration of [Bmim] $\mathrm{BF}_{4}$ less than $3.54 \mathrm{~g} / \mathrm{L}$. When the glucose-rich phase was recycled to ferment, the toxicity of residual [Bmim] $\mathrm{BF}_{4}$ to cell growth was thus negligible. Furthermore, ILtolerant microorganisms and microbial communities recently have recently been discovered in environmental samples, and studies have begun to elucidate mechanisms of ILs tolerance (Yu et al. 2016).

Cells, soluble proteins, and pigments were also extracted using a multi-stage sugaring-out extraction. The total removal ratio of cells, soluble proteins, and pigments decreased with increasing extraction stage due to them being distributed to the top phase, as compared to each stage of sugaring-out extraction. As a result, the total removal ratio of cells and pigments from the unfiltered broth was $68.4 \%$ and $65.4 \%$, respectively. The filtered broth had a slightly higher removal ratio of cells of $70.6 \%$ and a slightly lower removal ratio of pigments of $57.0 \%$. Because of the lack of salting-out and solvent precipitation, the IL-based sugaring-out extraction system performed poorly for soluble protein removal when compared to solvent-based salting-out and sugaring-out extraction. Only about $10 \%$ soluble proteins were removed in the three-stage IL-based sugaring-out 
extraction. The salting-out extraction system of acetone and ammonium sulfate can remove $90.8 \%$ soluble proteins from succinic acid fermentation broth (Sun et al. 2014). Furthermore, $61.3 \%$ soluble proteins was removed from lactic acid fermentation broth using isopropanol/ glucose sugaring-out extraction system (Yan et al. 2016).

Recently, IL-based ATPS have been successfully used in the extraction, concentration, and purification of the most diverse biomolecules, including proteins, enzymes, antioxidants, synthetic and fermentative produced drugs, and biochemicals. However, most ILs are still expensive in comparison with more conventional solvents. In industrial applications, ILs are inevitably mixed with other solvents or products. Therefore, the development of efficient separation and recycling routes is a crucial attempt to decrease costs and their environmental footprint. Some remarkable achievement for ILs recycling was obtained, which supports establishing an IL-based ATPS as a sound basis of greener cost-effective strategies with sustainable development (Claudio et al. 2014). In this study, multi-stage sugaring-out extraction was applied to obtain higher lactic acid extractability. Objectively speaking, multi-stage sugaring-out extraction is more accessible to achieve on a laboratory scale than continuous counter-current sugaring-out extraction. However, in industrial application, continuous countercurrent sugaring-out extraction is a feasible and effective strategy for the separation of target products.

\section{Conclusions}

In this study, ionic liquid-based sugaring-out extraction was developed and investigated to separate lactic acid from synthetic solution and lignocellulose-derived fermentation broth. Except for $\left[\mathrm{E}_{\mathrm{OH}} \mathrm{mim}\right] \mathrm{BF}_{4}$, the ILs with $\mathrm{BF}_{4}{ }^{-}$and $\mathrm{OTF}^{-}$anion can form aqueous two-phase systems with the aid of saccharides. Due to the decrease in ILs' kosmotropicity, the ATPS formation ability of ILs could be promoted by increasing the side-chain length of ILs in the order of $[\mathrm{Hmim}] \mathrm{BF}_{4} \approx[\mathrm{Bmim}] \mathrm{BF}_{4}{ }^{>}[\mathrm{Emim}] \mathrm{BF}_{4}$ with the same kind of saccharides. On the other hand, for the same type of ILs, an ATPS was formed more easily with glucose than with xylose. About $51.8 \%$ LA and 92.3\% [Bmim] $\mathrm{BF}_{4}$ were partitioned to the top phase, and 97.0\% glucose was extracted to the bottom phase at a sugaring-out extraction system consisting of $25 \%(\mathrm{w} / \mathrm{w})$ glucose and $45 \%(\mathrm{w} / \mathrm{w})$ IL at $\mathrm{pH} 2.0$. The total recovery of LA would increase to $89.0 \%$ in three-stage sugaring-out extraction from synthetic solution. In three-stage sugaring-out extraction from filtered and unfiltered fermentation broth obtained via SSCF of acid-pretreated CS, the total recovery of LA was $89.5 \%$ and $89.4 \%$, respectively. Meanwhile, the total removal ratio of cells and pigments from the unfiltered broth was $68.4 \%$ and $65.4 \%$, respectively. Although the lactic acid extractability for one stage of IL-based sugaring-out extraction is lower than that of organic solvent-based sugaring-out extraction, the glucose-rich phase with low toxicity of ILs coupled with upstream fermentation technology deserves a promising strategy for lactic acid production.

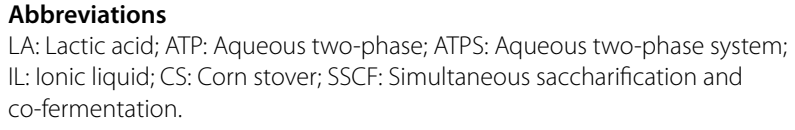

\section{Acknowledgements}

Not applicable.

\section{Authors' contributions}

$X Z$ designed and carried out the experiments, and analyzed results. YQS drafted and revised the manuscript. HJZ carried out the experiments and analyzed results. HJL, XYW, YX, and YL advised on the experiments design. $Z L X$ and $Y T$ revised the manuscript. All authors read and approved the final manuscript.

\section{Funding}

This work was supported by the National Natural Science Foundation of China [Grant Number 22078043].

Availability of data and materials

All data generated or analyzed during this study are included in this article.

\section{Declarations}

Ethics approval and consent to participate

Not applicable.

\section{Consent for publication}

All the authors approved the consent for publishing the manuscript to Bioresources and Bioprocessing.

\section{Competing interests}

The authors declare no competing interests.

Received: 7 October 2021 Accepted: 6 December 2021

Published online: 13 December 2021

\section{References}

Ahmad A, Banat F, Taher $\mathrm{H}$ (2020) A review on the lactic acid fermentation from low-cost renewable materials: recent developments and challenges. Environ Technol Innovation 20:101138. https://doi.org/10.1016/j.eti.2020. 101138

Aydogan O, Bayraktar E, Mehmetoglu U (2011) Aqueous two-phase extraction of lactic acid: optimization by response surface methodology. Sep Sci Technol 46(7):1164-1171. https://doi.org/10.1080/01496395.2010.550270

Chen YH, Wang YG, Cheng QY, Liu XL, Zhang SJ (2009) Carbohydrates-tailored phase tunable systems composed of ionic liquids and water. J Chem Thermodyn 41(9):1056-1059. https://doi.org/10.1016/j.jct.2009.04.008

Choi JH, Kim SH, Moon SH (2002) Recovery of lactic acid from sodium lactate by ion substitution using ion-exchange membrane. Sep Purif Technol 28(1):69-79. https://doi.org/10.1016/S1383-5866(02)00014-X

Claudio AFM, Marques CFC, Boal-Palheiros I, Freire MG, Coutinho JAP (2014) Development of back-extraction and recyclability routes for ionic-liquidbased aqueous two-phase systems. Green Chem 16(1):259-268. https:// doi.org/10.1039/c3gc41999a

Dai JY, Liu CJ, Xiu ZL (2015) Sugaring-out extraction of 2,3-butanediol from fermentation broths. Process Biochem 50(11):1951-1957. https://doi.org/ 10.1016/j.procbio.2015.08.004 
Dai JY, Ma LH, Wang ZF, Guan WT, Xiu ZL (2017) Sugaring-out extraction of acetoin from fermentation broth by coupling with fermentation. Bioprocess Biosyst Eng 40(3):423-429. https://doi.org/10.1007/s00449-016-1710-x

Dai JY, Sun YQ, Xiu ZL (2021) lonic liquid-based salting-out extraction of biochemicals. Chin J Chem Eng 30:185-193. https://doi.org/10.1016/j.cjche. 2020.11 .004

Fu HX, Sun YQ, Teng H, Zhang DJ, Xiu ZL (2015) Salting-out extraction of carboxylic acids. Sep Purif Technol 139:36-42. https://doi.org/10.1016/j. seppur.2014.11.001

Ganske F, Bornscheuer UT (2006) Growth of Escherichia coli, Pichia pastoris and

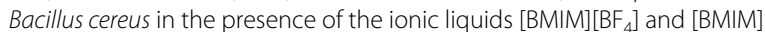
$\left[\mathrm{PF}_{6}\right]$ and organic solvents. Biotechnol Lett 28(7):465-469. https://doi.org/ 10.1007/s10529-006-0006-7

Han X, Armstrong DW (2007) lonic liquids in separations. Acc Chem Res 40(11):1079-1086. https://doi.org/10.1021/ar700044y

Isikgor FH, Becer CR (2015) Lignocellulosic biomass: a sustainable platform for the production of bio-based chemicals and polymers. Polym Chem 6(25):4497-4559. https://doi.org/10.1039/c5py00263j

Kaar JL, Jesionowski AM, Berberich JA, Moulton R, Russell AJ (2003) Impact of ionic liquid physical properties on lipase activity and stability. J Am Chem Soc 125(14):4125-4131. https://doi.org/10.1021/ja028557x

Komesu A, Maciel MRW, de Oliveira JAR, Martins LHD, Maciel R (2017) Purification of lactic acid produced by fermentation: focus on non-traditional distillation processes. Sep Purif Rev 46(3):241-254. https://doi.org/10. 1080/15422119.2016.1260034

Lan K, Xu S, Li J, Hu C (2019) Recovery of lactic acid from corn stover hemicellulose-derived liquor. ACS Omega 4(6):10571-10579. https://doi.org/10. 1021/acsomega.9b00794

Li CX, Han J, Wang Y, Yan YS, Xu XH, Pan JM (2009) Extraction and mechanism investigation of trace roxithromycin in real water samples by use of ionic liquid-salt aqueous two-phase system. Anal Chim Acta 653:178-183. https://doi.org/10.1016/j.aca.2009.09.011

Lightfoot EN, Moscariello JS (2004) Bioseparations. Biotechnol Bioeng 87(3):259-273. https://doi.org/10.1002/bit.20111

Matsumoto M, Takahashi T, Fukushima K (2003) Synergistic extraction of lactic acid with alkylamine and tri-n-butylphosphate: effects of amines, diluents and temperature. Sep Purif Technol 33(1):89-93. https://doi.org/10.1021/ acsomega.9b00794

Matsumoto M, Takemori S, Tahara Y (2020) Lactic acid permeation through deep eutectic solvents-based polymer inclusion membranes. Membranes 10(9):244. https://doi.org/10.3390/membranes 10090244

Meng KX, Zhang GY, Ding CQ, Zhang TY, Yan H, Zhang DP, Fang TQ, Liu MY, You ZC, Yang CH, Shen J, Jin X (2020) Recent advances on purification of lactic acid. Chem Rec 20(11):1236-1256. https://doi.org/10.1002/tcr.202000055

Muller A, Schulz R, Wittmann J, Kaplanow I, Gorak A (2013) Investigation of a phosphate/1-butyl-3-methylimidazolium trifluoromethanesulfonate/ water system for the extraction of 1,3-propanediol from fermentation broth. RSC Adv 3(1):148-156. https://doi.org/10.1039/c2ra22619g

Oliveira FS, Araujo JMM, Ferreira R, Rebelo LPN, Marrucho IM (2012) Extraction of L-lactic, L-malic, and succinic acids using phosphonium-based ionic liquids. Sep Purif Technol 85:137-146. https://doi.org/10.1016/j.seppur. 2011.10.002

Pernak J, Sobaszkiewicz K, Mirska I (2003) Anti-microbial activities of ionic liquids. Green Chem 5:52-56. https://doi.org/10.1039/B207543C

Pratiwi Al, Yokouchi T, Matsumoto M, Kondo K (2015) Extraction of succinic acid by aqueous two-phase system using alcohols/salts and ionic liquids/ salts. Sep Purif Technol 155:127-132. https://doi.org/10.1016/j.seppur. 2015.07.039

Song ZY, Sun YQ, Wei BC, Xiu ZL (2013) Two-step salting-out extraction of 1,3-propanediol and lactic acid from the fermentation broth of Klebsiella pneumoniae on biodiesel-derived crude glycerol. Eng Life Sci 13(5):487495. https://doi.org/10.1002/9781118845394.ch11

Sui H, Zhou JJ, Ma GQ, Niu YQ, Cheng J, He L, Li XG (2018) Removal of ionic liquids from oil sands processing solution by ion-exchange resin. Appl Sci 8:1611. https://doi.org/10.3390/app8091611

Sun YQ, Yan L, Fu HX, Xiu ZL (2014) Salting-out extraction and crystallization of succinic acid from fermentation broths. Process Biochem 49(3):506-511. https://doi.org/10.1016/j.procbio.2013.12.016

Sun YQ, Zhang SS, Zhang XX, Zheng YF, Xiu ZL (2018) lonic liquid-based sugaring-out and salting-out extraction of succinic acid. Sep Purif Technol 204:133-140. https://doi.org/10.1016/j.seppur.2018.04.064
Sun YQ, Zhang XX, Zheng YF, Yan L, Xiu ZL (2019) Sugaring-out extraction combining crystallization for recovery of succinic acid. Sep PurifTechnol 209:972-983. https://doi.org/10.1016/j.seppur.2018.09.049

Sun YQ, Li XY, Wei CX, Qi WB, Xiu ZL (2021) An aptly industrialized bioprocess for lactic acid production from corn stover using thermotolerant microbial consortia. Bioprocess Biosyst Eng 44:2445-2454. https://doi.org/10. 1007/s00449-021-02616-5

Tang B, Tian M, Row KH (2013) Adsorption of lactic acid onto three ionic liquidmodified porous polymers. J Appl Polym Sci 129(3):1306-1313. https:// doi.org/10.1002/app.38813

Trindade JR, Visak ZP, Blesic M, Marrucho IM, Coutinho JAP, Canongia Lopes JN, Rebelo PN (2007) Salting-out effects in aqueous ionic liquid solutions: cloud-point temperature shifts. J Phys Chem B 111:4737-4741. https:// doi.org/10.1021/jp067022d

Wakisaka A, Ohki T (2005) Phase separation of water-alcohol binary mixtures induced by the microheterogeneity. Faraday Discuss 129:231-245. https://doi.org/10.1039/b405391e

Wang B, Ezejias T, Feng H, Blaschek H (2008a) Sugaring-out: a novel phase separation and extraction system. Chem Eng Sci 63(9):2595-2600. https://doi.org/10.1016/j.ces.2008.02.004

Wang B, Feng H, Ezeji T, Blaschek H (2008b) Sugaring-out separation of acetonitrile from its aqueous solution. Chem Eng Technol 31 (12):1869-1874. https://doi.org/10.1002/ceat.200800003

Wang XL, Nie Y, Zhang XP, Zhang SJ, Li JW (2012) Recovery of ionic liquids from dilute aqueous solutions by electrodialysis. Desalination 285:205-212. https://doi.org/10.1016/j.desal.2011.10.003

Wang JF, Luo JQ, Zhang XP, Wan YH (2016) Concentration of ionic liquids by nanofiltration for recycling: filtration behavior and modeling. Sep Purif Technol 165:18-26. https://doi.org/10.1016/j.seppur.2016.03.042

Wu B, Zhang YM, Wang HP (2008a) Aqueous biphasic systems of hydrophilic ionic liquids plus sucrose for separation. J Chem Eng Data 53(4):983-985. https://doi.org/10.1021/je700729p

Wu B, Zhang YM, Wang HP (2008b) Phase behavior for ternary systems composed of ionic liquid plus saccharides plus water. J Phys Chem B 112(20):6426-6429. https://doi.org/10.1021/jp8005684

Xu SG, Lan KQ, Li JM, He T, Hu CW (2018) Separation of lactic acid from synthetic solutions and the mixture directly derived from corn stover by aqueous two phase extraction. Sep Purif Technol 204:281-289. https:// doi.org/10.1016/j.seppur.2018.04.086

Yan L, Sun YQ, Xiu ZL (2016) Sugaring-out extraction coupled with fermentation of lactic acid. Sep Purif Technol 161:152-158. https://doi.org/10. 1016/j.seppur.2016.01.049

Yan L, Sun YQ, Wang XD, Fu HX, Mu Y, Xiu ZL (2018) Partition behavior of monocarboxylic acids in salting-out extraction systems of monohydric alcohols and dipotassium phosphate. Sep Purif Technol 199(30):351-358. https://doi.org/10.1016/.seppur.2018.02.006

Yankov DS, Trusler JPM, Yordanov BY, Stateva RP (2008) Influence of lactic acid on the formation of aqueous two-phase systems containing poly(ethylene glycol) and phosphates. J Chem Eng Data 53(6):1309-1315. https://doi.org/10.1021/je800016r

Yu CW, Simmons BA, Singer SW, Thelen MP, VanderGheynst JS (2016) Ionic liquid-tolerant microorganisms and microbial communities for lignocellulose conversion to bioproducts. Appl Microbiol Biotechnol 100(24):10237-10249. https://doi.org/10.1007/s00253-016-7955-0

Yuan SF, Hsu TC, Wang CA, Jang MF, Kuo YC, Alper HS, Guo GL, Hwang WS (2018) Production of optically pure I(+)-lactic acid from waste plywood chips using an isolated thermotolerant Enterococcus faecalis S/ at a pilot scale. J Ind Microbiol Biotechnol 45(11):961-970. https://doi.org/10.1007/ s10295-018-2078-5

Zhang YQ, Zhang SJ, Chen YH, Zhang JM (2007) Aqueous biphasic systems composed of ionic liquid and fructose. Fluid Phase Equilib 257(2):173176. https://doi.org/10.1016/j.fluid.2007.01.027

Zhang Y, Qian Z, Liu P, Liu L, Zheng Z, Ouyang J (2018) Efficient in situ separation and production of L-lactic acid by Bacillus coagulans using weak basic anion-exchange resin. Bioprocess Biosyst Eng 41(2):205-212. https://doi.org/10.1007/s00449-017-1858-z

\section{Publisher's Note}

Springer Nature remains neutral with regard to jurisdictional claims in published maps and institutional affiliations. 